\title{
IMPLANTAÇÃO DO PRONATEC EM UMA ESCOLA TÉCNICA VINCULADAA UMA UNIVERSIDADE FEDERAL: NASCIMENTO, MATURIDADE E DECLÍNIO
}

\author{
IMPLANTATION OF PRONATEC IN A TECHNICAL SCHOOL LINKED TO A FEDERAL \\ UNIVERSITY: BIRTH, MATURITY AND DECLINE
}

\author{
IMPLANTACIÓN DEL PRONATEC EN UNA ESCUELA TÉCNICA VINCULADA A UNA \\ UNIVERSIDAD FEDERAL: NACIMIENTO, MATURIDAD Y DECLINIO
}

Núbia Nogueira de Freitas Vogado

E-mail: nubianog@gmail.com

Elisa Antonia Ribeiro

E-mail: ribeielisa@gmail.com

Instituto Federal de Educação, Ciência e Tecnologia do Triângulo Mineiro

\begin{abstract}
RESUMO
O presente artigo trata do processo de implantação do Programa Nacional de Acesso ao Ensino Técnico e Emprego (Pronatec) aprofundado sob a perspectiva de uma escola técnica vinculada a uma universidade federal dentre tantas instituições ofertantes. A metodologia empregada foi a revisão da literatura com base em autores que vem discutindo essa temática e complementada com a pesquisa documental realizada por meio da análise de documentos institucionais sobre o programa no portal da instituição publicados durante os anos de 2012 a 2016. Ascender à discussão sobre o processo de condução e de avaliação dos resultados desse programa no contexto empírico de uma escola técnica vinculada a uma universidade federal está relacionado com as reflexões da criação do Pronatec como política de governo, que mantem estreito vínculo ideológico com as coordenadas dos organismos internacionais que passam a ditar as orientações educacionais aos países em desenvolvimento nos últimos 30 anos. Evidencia-se que não houve uma preocupação com as mudanças estruturais necessárias na sociedade para amenizar as desigualdades sociais, e sim uma política de proporcionar formações rápidas.
\end{abstract}

PALAVRAS CHAVE: Políticas Públicas. Pronatec. Estudo de Caso.

\section{ABSTRACT}

This article deals with the process of implementation of the National Program of Access to Technical Education and Employment (Pronatec) in depth from the perspective of a technical school linked to a federal university among many offering institutions. The methodology used was the review of the literature based on authors who have been discussing this theme and complemented with the documentary research carried out through the analysis of institutional documents about the program in the institution's portal published during from the years 2012 to 2016. To focus on the process of conducting and evaluating the results of this program in the empirical context of a technical school linked to a federal university is related to the reflections of the creation of Pronatec as a government policy, which maintains ideological link with the coordinates of the international organisms that have come to dictate the educational guidelines to the developing countries in the last 30 years. There is evidence that there was no concern with the necessary structural changes in society to alleviate social inequalities, rather a policy of providing rapid training.

KEYWORDS: Public Policies. Pronatec. Case study.

\begin{tabular}{|l|l|l|l|l|l} 
(C) Revista Triângulo & Uberaba, Minas Gerais & Vol. 12 & n.2 & p. 51 - 72 & 2019 \\
\hline
\end{tabular}




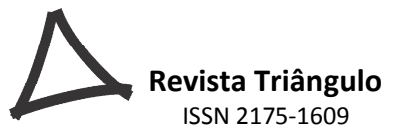

ISSN 2175-1609

\begin{abstract}
RESUMÉN
El presente artículo trata del proceso de implantación del Programa Nacional de Acceso a la Enseñanza Técnica y Empleo (Pronatec) profundizado bajo la perspectiva de una escuela técnica vinculada a una universidad federal entre tantas instituciones ofertantes. La metodología empleada fue la revisión de la literatura con base en autores que viene discutiendo esa temática y complementada con la investigación documental realizada por medio del análisis de documentos institucionales sobre el programa en el portal de la institución publicados durante los años de 2012 hasta 2016. Encender la discusión sobre el proceso de conducción y de evaluación de los resultados de ese programa en el contexto empírico de una escuela técnica vinculada a una universidad federal está relacionada con las reflexiones de la creación del Pronatec como política de gobierno que mantiene un estrecho vínculo ideológico con las coordenadas de los organismos internacionales que pasan a dictar las orientaciones educativas a los países en desarrollo en los últimos 30 años. Indicio que no hubo una preocupación con los cambios estructurales necesarios en la sociedad para amenizar las desigualdades sociales, si una política de ofrecer formaciones.
\end{abstract}

PALABRAS CLAVE: Políticas Públicas. Pronatec. Estudio de Caso.

\title{
1. INTRODUÇÃO
}

Considerando que o Programa Nacional de Acesso ao Ensino Técnico e Emprego (Pronatec), desde sua criação em 2011, no governo Dilma Rousseff, vem sendo tratado como política pública para fomento da educação profissional e tecnológica, a pesquisa que originou este artigo teve como intuito conhecer e entender a implantação e execução deste programa sob o ponto de vista de uma de suas instituições ofertantes, por meio de pesquisas bibliográfica e documental.

O recorte temporal analisado foi de cinco anos, a partir de 2012 - quando se deu a efetiva implantação do programa na instituição - até 2016 - em cujos meados a responsabilidade do Governo Federal havia sido transferida para o presidente Michel Temer. Dentro deste recorte temporal, para cada ano, especificamente, foram feitas duas análises: uma voltada ao alunado e outra aos recursos humanos.

Como resultado, o artigo aponta que a instituição objeto desta análise, enquanto ofertante do Pronatec, desde a implantação ao início de um declínio, passou por diversas fases intimamente relacionadas a um inconstante cenário brasileiro, tanto econômico quanto político, em meio a esse período de transitoriedade e incertezas. 


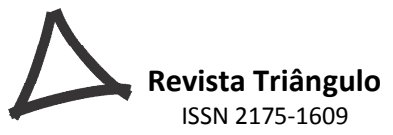

\section{REFERENCIAL TEÓRICO}

De acordo com a Lei $n^{\circ} .12 .513$ de 26 de outubro de 2011, que instituiu o Pronatec, a execução do mesmo ficaria a cargo da União, sendo que sua finalidade era a de ampliar a oferta da educação profissional e tecnológica por meio de programas, projetos e ações de assistência técnica e financeira. Além disso, a lei também apresentava os objetivos do Pronatec, a saber:

I - expandir, interiorizar e democratizar a oferta de cursos de educação profissional técnica de nível médio presencial e a distância e de cursos e programas de formação inicial e continuada ou qualificação profissional; II fomentar e apoiar a expansão da rede física de atendimento da educação profissional e tecnológica; III - contribuir para a melhoria da qualidade do ensino médio público, por meio da articulação com a educação profissional; IV - ampliar as oportunidades educacionais dos trabalhadores, por meio do incremento da formação e qualificação profissional; V - estimular a difusão de recursos pedagógicos para apoiar a oferta de cursos de educação profissional e tecnológica. VI - estimular a articulação entre a política de educação profissional e tecnológica e as políticas de geração de trabalho, emprego e renda (BRASIL, 2011).

Para atender à finalidade e aos objetivos propostos, a legislação também determinava que o programa deveria atuar em regime de colaboração entre a União, os Estados, o Distrito Federal e os Municípios, com a participação voluntária dos serviços nacionais de aprendizagem, de instituições privadas e públicas de ensino superior, de instituições de educação profissional e tecnológica e de fundações públicas de direito privado precipuamente dedicadas à educação profissional e tecnológica.

Quanto às modalidades de educação profissional e tecnológica o Pronatec deveria investir nos cursos de formação inicial e continuada (FIC) ou qualificação profissional com mínimo de 160 horas $^{2}$ e relacionados pelo Ministério da Educação (MEC); nos cursos de educação técnica de nível médio que "submetem-se às diretrizes curriculares nacionais definidas pelo Conselho Nacional de Educação" (BRASIL, 2011a, p. 1) e, nos cursos cuja bolsa-formação é definida especificamente nos termos de ato do Ministro de Estado da Educação, classificados como de formação de professores em nível médio na modalidade normal. 


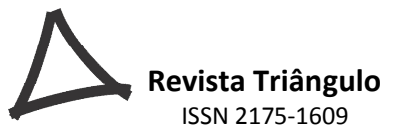

ISSN 2175-1609

Com relação aos cursos de educação técnica de nível médio, a princípio o governo exigiu, como condição prévia para disponibilização de recursos, o que ele chama de articulação do ensino médio com a educação profissional técnica na modalidade concomitante. Ou seja, o estudante deveria possuir duas matrículas: uma para o ensino médio e outra para o curso técnico, em instituições distintas. Posteriormente o programa passou a contemplar outras duas formas de educação profissional técnica de nível médio: a integrada e a subsequente. Na primeira, o estudante deveria cursar o ensino médio integrado ao técnico em uma única instituição, por conseguinte, teria apenas uma matrícula, pois o currículo seria integrado. Na segunda, o foco seria no estudante que já concluiu o ensino médio e desejava apenas cursar o ensino técnico.

Em relação à estrutura e operacionalização do programa, ou seja, às questões práticas que permitiram sua implantação, é importante destacar alguns aspectos. O primeiro deles é relativo aos três agentes necessários ao seu funcionamento, que são o Governo Federal, detentor dos recursos e financiador do programa; as instituições ofertantes que, autorizadas pelo primeiro, de fato executam o programa; e, por fim, as instituições demandantes, que apresentam as demandas por formação com base nas necessidades da população de uma determinada localidade. Nessa relação existe, de um lado, dentre as instituições ofertantes, as que são pertencentes à Rede Federal e que, de fato, cooperam com o programa por meio de Termo de Cooperação, e outras que, públicas ou não, apenas aderem ao programa por meio de Termo de Adesão; e de outro lado, dentre as instituições demandantes, os ministérios ou outros órgãos da Administração Pública Federal que, efetivamente, celebram Acordo de Cooperação Técnica, além das secretarias estaduais e distrital de educação e de outras vinculadas ao MEC, que apenas firmam Termo de Adesão como parceiros demandantes.

Pode-se eleger o financiamento como outra questão prática por ser parte fundamental em toda política pública. Para tanto, por meio da Portaria 817, de 13 de agosto de 2015, foi criada a Bolsa-Formação, em duas vertentes: uma destinada a estudantes de nível médio para qualificação em cursos de educação profissional técnica, e outra destinada a trabalhadores para qualificação em cursos de formação inicial e continuada (BRASIL, 2015).

Outra questão prática a ser observada é referente à expressão pactuação, muito utilizada nos textos oficiais do programa. Trata-se da efetiva quantidade de vagas da Bolsa- 


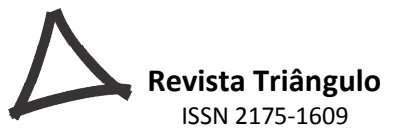

ISSN 2175-1609

Formação disponíveis em um Termo de Cooperação ou em um Termo de Adesão para que uma instituição ofertante, de fato, possa cumprir sua missão para com o programa e a sociedade. Quando pactuadas, essas vagas ficavam disponíveis em ambiente virtual para que o estudante ou o trabalhador interessado em se qualificar pudesse fazer sua inscrição. Após inscrição, a vaga ficava reservada, por dois dias, para que o interessado procurasse o ofertante com todos os documentos comprobatórios de sua condição de estudante ou de trabalhador, e efetivasse sua inscrição por meio da matrícula.

E por fim, outra questão prática necessária à compreensão do Pronatec refere-se à constituição jurídica das instituições ofertantes. Dentre elas destacam-se as escolas técnicas vinculadas às universidades federais (ETVUFs) que, segundo o Glossário da Plataforma Nilo Peçanha Ano Base 2017, podem ser compreendidas como instituições de Educação Profissional, Científica e Tecnológica (PNP, 2018) e, por sua vez, componentes dessa Rede Federal. Embora possuam autonomia administrativa, financeira e orçamentária, são ligadas às universidades federais. Assim como os Institutos Federais, as ETVUFs são subordinadas à Secretaria de Educação Profissional e Tecnológica do Ministério da Educação (SETECMEC), de onde são viabilizados os orçamentos, destinados especificamente ao ensino profissional, mas administrados pela conta única da universidade federal a qual se vinculam. No Brasil são apenas 26 escolas nesse formato.

De forma geral é possível afirmar que o Pronatec teve como mote a ampliação do acesso à educação profissional para jovens e trabalhadores brasileiros, conforme declarado pela própria Dilma Rousseff em diversos pronunciamentos, dentre eles na entrevista concedida a Luciano Seixas no programa de rádio Café com a Presidenta, no início de 2011 (BRASIL, 2011b). Entretanto, diversos autores que estudam as políticas públicas voltadas para a educação profisssional apresentam críticas às mesmas, principalmente quando elas são analisadas e problematizadas à luz da situação econômica, política e social, tanto nacional como mundial.

A propósito, analisando as políticas públicas anteriores voltadas para a educação profissional, Brandão (2009) já asseverava que o Governo Federal, desde a gestão de Fernando Henrique Cardoso, vem tratando a Educação Profissional e Tecnológica no Brasil como política pública subordinada aos interesses de organismos internacionais, "procurando 


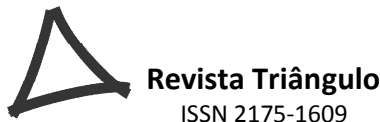

ISSN 2175-1609

guiar sua consciência pelo acesso ao consumo, numa falsa ilusão de ascensão social" (BRANDÃO, 2009, p. 35).

Lima (2012), por sua vez, ressalta que "ao incluir a qualificação profissional, mesmo com a carga horária mínima de 160 horas, [o programa] não garante a elevação de escolaridade como exigência, assim como consta nos cursos FIC" (LIMA, 2012, p. 83). Ademais, ao se referir à enorme abrangência de ações do programa e aplicações de seus recursos, afirma que o mesmo "não faz distinção setorial (setores produtivos) ou institucional (público e privado, instituições $\mathrm{A}, \mathrm{B}$ ou $\mathrm{C}$ ) entre aquilo que tem sido o papel fundamental da rede pública federal (a educação profissional técnica) e o que tem sido o campo privilegiado da rede 'privada' do sistema 'S'” (LIMA, 2012, p. 82). Para Castro e Barbosa (2013), a oferta de cursos na modalidade concomitante não possibilita uma formação significativa e emancipadora, mas sim uma formação totalmente fragmentada. Finalmente, Reis (2017) salienta que

[...] o arranjo institucional do PRONATEC o caracterizou enquanto política educacional compensatória, que vem tentando, ao longo da sua existência, suprir os aspectos estruturais do desemprego por meio de medidas conjunturais, ou seja, via qualificação profissional, o que é insuficiente e inconsistente face às demandas concretas da classe trabalhadora brasileira. (REIS, 2017, p. 187)

Nota-se que, na concepção desses autores, as políticas públicas voltadas para a educação profissional visam, em primeiro plano, atender às exigências da economia e do mercado, não preocupando-se, necessariamente, com as reais necessidades dos trabalhadores ou futuros trabalhadores.

\section{MATERIAIS E MÉTODOS}

Feitas essas considerações que perpassaram pelos aspectos legais do Pronatec, por sua operacionalização e pela perspectiva de teóricos que se debruçaram sobre a temática, este artigo adentrou os muros de uma instituição escolar específica que vivenciou a oferta do programa para conhecê-lo e analisá-lo a partir do alunado e dos colaboradores selecionados. 


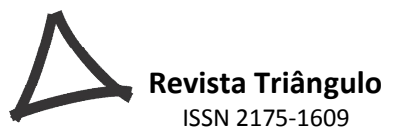

ISSN 2175-1609

O Centro de Educação Profissional - Cefores, escola técnica vinculada à Universidade Federal do Triângulo Mineiro - UFTM, objeto desta análise, é a única ETVUF no município de Uberaba, Minas Gerais. Criada em junho de 1990 como Centro de Formação Especial de $2^{\circ}$ Grau em Saúde, sua nomenclatura já denotava, àquela época, uma particularidade institucional que era a oferta de cursos nesta área do conhecimento: Enfermagem, Farmácia, Nutrição, Patologia e Radiologia.

Diante das novas demandas do mercado de trabalho, a partir de 2011 o Cefores acrescentou a oferta de outros cursos técnicos não vinculados à área da Saúde, como Segurança do Trabalho e Informática, motivo pelo qual alterou sua denominação para Centro de Educação Profissional, optando, porém, por manter inalterada a sigla já consolidada e que demarcava sua identidade institucional.

Atualmente a escola oferta, semestralmente, vagas regulares para cursos técnicos, condicionadas à disponibilidade de corpo docente e de infraestrutura física, sendo eles: Análises Clínicas, Enfermagem, Farmácia, Informática, Radiologia, Saúde Bucal e Segurança do Trabalho. Em 2012, o Cefores assinou Termo de Cooperação com o Governo Federal para execução do Pronatec na condição de instituição ofertante.

A coleta de dados foi feita por meio de consultas aos Relatórios de Gestão de Exercícios ${ }^{1}$ e aos Editais de Seleção de Profissionais para o programa no portal da instituição. Com relação aos editais, foram construídas tabelas-resumo, uma para cada ano, contendo as principais demandas e informações, como encargos, quantidade e destinação das vagas, número de fases e validade das seleções.

\section{ANÁLISE DOS DADOS E RESULTADOS}

\subsection{Implantação (2012)}

A instituição acompanhou o Pronatec, desde o início, por meio de reuniões no MEC e junto a esse acompanhamento iniciou a sua implantação no âmbito institucional. Segundo o Relatório de Gestão do Exercício de 2012 da UFTM, o intuito da adesão ao Pronatec foi o de 


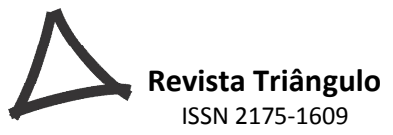

ISSN 2175-1609

ampliar a oferta de cursos técnicos (UFTM, 2013). Esse é um dos objetivos estratégicos do Cefores no âmbito da instituição a qual se vincula e o que se percebe é que o programa, do ponto de vista institucional, foi implantado para contribuir na consecução dos mesmos.

Em 2012, com uma estrutura bem simples de que dispunha o próprio Cefores no âmbito da UFTM, foram ofertadas, por meio do programa, 3 novas turmas de cursos técnicos que a instituição já ofertava regularmente há alguns anos, no entanto, todos na modalidade concomitante, em conformidade com a determinação do MEC na ocasião, além de cursos de qualificação na modalidade FIC. Em sua primeira pactuação o Cefores matriculou 228 alunos, sendo 143 em cursos de qualificação e 85 em cursos técnicos concomitantes, representando $62,72 \%$ e $37,28 \%$ da referida pactuação, respectivamente. Segundo o mesmo relatório, e considerando que o Cefores teve um alunado regular de 397 matriculados em 2012 (UFTM, 2013), o alunado do programa representou 36,48\% do alunado geral da instituição logo no seu ano de implantação.

A análise dos editais de seleção de pessoal de 2012 permite concluir que a gestão da instituição, e consequentemente, do programa, encontrava-se em fase de adaptação. Os recursos humanos utilizados para permitir a execução do programa nesse ano foram se formando por meio de 8 editais de seleção, todos em fase única de análise curricular e com seis meses de validade, conforme a Tabela 1 a seguir. Os editais 38 e 39 selecionaram, ao todo e de imediato, 47 profissionais, representando 82,46\% das seleções do ano. Ainda no ano de 2012, outros 10 profissionais (17,54\%) foram selecionados e distribuídos em outros 6 editais cujos números de vagas variaram apenas de 1 a 3 profissionais. No início, os processos só poderiam selecionar servidores ativos e aposentados da própria instituição, o que, de fato, ocorreu em 5 processos. No edital 54 já foi permitida a inclusão de servidores ativos e aposentados do Instituto Federal de Educação, Ciência e Tecnologia do Triângulo Mineiro (IFTM) na sua destinação. E os últimos editais deste ano, 55 e 56, ampliaram suas destinações deixando as candidaturas sem restrições quanto a vínculo ao serviço público. 


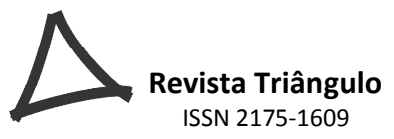

ISSN 2175-1609

Tabela 1 - Processos seletivos de profissionais do Pronatec-UFTM no ano de 2012

\begin{tabular}{|c|c|c|c|c|c|c|}
\hline $\begin{array}{c}\text { Editais } \\
\text { PROEXT }^{3}\end{array}$ & Encargos & Vagas & Totais & Validade & Destinação & $\begin{array}{l}\text { Número } \\
\text { de fases }\end{array}$ \\
\hline \multirow{4}{*}{$\begin{array}{c}38 \text { de } \\
25 / 06 / 2012\end{array}$} & Supervisor & 07 & \multirow{4}{*}{22} & \multirow{4}{*}{6 meses } & \multirow{4}{*}{$\begin{array}{c}\text { servidores ativos e } \\
\text { aposentados da } \\
\text { UFTM }\end{array}$} & \multirow{4}{*}{01} \\
\hline & Orientador & 07 & & & & \\
\hline & Apoio sede & 05 & & & & \\
\hline & Apoio técnico & 03 & & & & \\
\hline $\begin{array}{c}39 \mathrm{de} \\
26 / 06 / 2012\end{array}$ & Professor & 25 & 25 & 6 meses & $\begin{array}{c}\text { servidores ativos e } \\
\text { aposentados da } \\
\text { UFTM }\end{array}$ & 01 \\
\hline $\begin{array}{c}42 \mathrm{de} \\
31 / 07 / 2012\end{array}$ & Professor & 01 & 01 & 6 meses & $\begin{array}{c}\text { servidores ativos e } \\
\text { aposentados da } \\
\text { UFTM }\end{array}$ & 01 \\
\hline \multirow{2}{*}{$\begin{array}{c}45 \mathrm{de} \\
20 / 08 / 2012\end{array}$} & Apoio sede & 01 & \multirow{2}{*}{02} & \multirow{2}{*}{6 meses } & \multirow{2}{*}{$\begin{array}{c}\text { servidores ativos e } \\
\text { aposentados da } \\
\text { UFTM }\end{array}$} & \multirow{2}{*}{01} \\
\hline & Apoio técnico & 01 & & & & \\
\hline $\begin{array}{c}46 \mathrm{de} \\
29 / 08 / 2012\end{array}$ & Professor & 02 & 02 & 6 meses & $\begin{array}{c}\text { servidores ativos e } \\
\text { aposentados da } \\
\text { UFTM }\end{array}$ & 01 \\
\hline $\begin{array}{c}54 \mathrm{de} \\
26 / 11 / 2012\end{array}$ & Professor & 03 & 03 & 6 meses & $\begin{array}{c}\text { servidores ativos e } \\
\text { aposentados da } \\
\text { UFTM e IFTM }\end{array}$ & 01 \\
\hline $\begin{array}{c}55 \mathrm{de} \\
29 / 11 / 2012 \\
\end{array}$ & Professor & 01 & 01 & 6 meses & pública & 01 \\
\hline $\begin{array}{c}56 \mathrm{de} \\
17 / 12 / 2012\end{array}$ & Professor & 01 & 01 & 6 meses & pública & 01 \\
\hline
\end{tabular}

Fonte: Elaborado pelas pesquisadoras em análise aos editais disponíveis no portal da UFTM na internet em www.uftm.edu.br/pronatec2/processos-encerrados, busca “2012”.

Neste primeiro ano foram selecionados professores ${ }^{4}$ para 33 disciplinas, 7 supervisores de curso, 7 orientadores, 6 apoios administrativos que revezavam apenas nas atividades de atendimento ao público e registro escolar, e 4 apoios técnicos que revezavam nas atividades acadêmicas dos cursos como estágios e aulas práticas.

\subsection{Expansão (2013)}

Em 2013 o programa iniciou o seu processo de expansão dentro da instituição, no entanto, ainda com pouca estrutura. Segundo o Relatório de Gestão do Exercício de 2013, com o oferecimento de 830 novas vagas foi possível matricular 735 alunos (UFTM, 2014), quantitativo que até então o Cefores não havia alcançado em suas ofertas regulares. Embora o 


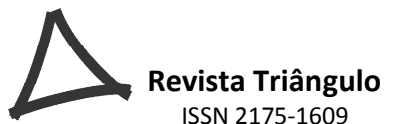

ISSN 2175-1609

documento não mencione a distribuição dessas matrículas em técnico ou FIC, observa-se um fortalecimento do programa no âmbito institucional. Exemplo disso é que no referido ano a instituição teve um quantitativo de 301 alunos inscritos nos cursos regulares sendo que somente as novas matrículas, por meio do programa, representaram mais que o dobro de alunos matriculados regularmente, sem contar aqueles que ainda continuaram vinculados ao programa na transição de 2012 para 2013.

Confirmando o início desse processo de expansão em 2013 estão os seus respectivos processos seletivos de profissionais, conforme a seguir:

Tabela 2 - Processos seletivos de profissionais do Pronatec-UFTM no ano de 2013

\begin{tabular}{|c|c|c|c|c|c|c|}
\hline $\begin{array}{c}\text { Editais } \\
\text { PROEXT } \\
\end{array}$ & Encargos & Vagas & Totais & Validade & Destinação & $\begin{array}{l}\text { Número } \\
\text { de fases }\end{array}$ \\
\hline $\begin{array}{c}03 \mathrm{de} \\
08 / 02 / 2013\end{array}$ & Professor & 03 & 03 & 6 meses & $\begin{array}{c}\text { servidores ativos e } \\
\text { aposentados da } \\
\text { UFTM e IFTM }\end{array}$ & 01 \\
\hline \multirow{2}{*}{$\begin{array}{c}05 \mathrm{de} \\
15 / 03 / 2013\end{array}$} & Orientador & 02 & \multirow{2}{*}{05} & \multirow{2}{*}{6 meses } & \multirow{2}{*}{$\begin{array}{l}\text { servidores ativos e } \\
\text { aposentados da } \\
\text { UFTM }\end{array}$} & \multirow{2}{*}{02} \\
\hline & Supervisor & 03 & & & & \\
\hline \multirow{2}{*}{$\begin{array}{c}24 \mathrm{de} \\
20 / 06 / 2013\end{array}$} & Supervisor & 02 & \multirow{2}{*}{14} & \multirow{2}{*}{1 ano } & \multirow{2}{*}{ pública } & \multirow{2}{*}{02} \\
\hline & Professor & 12 & & & & \\
\hline \multirow{5}{*}{$\begin{array}{c}25 \mathrm{de} \\
20 / 06 / 2013\end{array}$} & Apoio sede & 07 & \multirow{5}{*}{30} & \multirow{5}{*}{1 ano } & \multirow{5}{*}{$\begin{array}{l}\text { servidores ativos e } \\
\text { aposentados da } \\
\text { UFTM e ativos do } \\
\text { IFTM }\end{array}$} & \multirow{5}{*}{02} \\
\hline & Apoio técnico & 06 & & & & \\
\hline & Orientador & 04 & & & & \\
\hline & Sup. Administ. & 01 & & & & \\
\hline & Supervisor & 12 & & & & \\
\hline $\begin{array}{c}26 \mathrm{de} \\
20 / 06 / 2013\end{array}$ & Professor & 55 & 55 & 1 ano & $\begin{array}{l}\text { servidores ativos e } \\
\text { aposentados da } \\
\text { UFTM e ativos do } \\
\text { IFTM e da rede } \\
\text { estadual de ensino }\end{array}$ & 02 \\
\hline \multirow{4}{*}{$\begin{array}{c}34 \mathrm{de} \\
05 / 09 / 2013\end{array}$} & Apoio compras & 01 & \multirow{4}{*}{16} & \multirow{4}{*}{1 ano } & \multirow{4}{*}{$\begin{array}{c}\text { servidores ativos e } \\
\text { aposentados da } \\
\text { UFTM }\end{array}$} & \multirow{4}{*}{02} \\
\hline & Apoio finanças & 01 & & & & \\
\hline & Apoio técnico & 04 & & & & \\
\hline & Professor & 09 & & & & \\
\hline $\begin{array}{c}35 \mathrm{de} \\
05 / 09 / 2013 \\
\end{array}$ & Professor & 15 & 15 & 1 ano & pública & 02 \\
\hline \multirow{4}{*}{$\begin{array}{c}36 \mathrm{de} \\
02 / 10 / 2013\end{array}$} & Apoio sede & 01 & \multirow{4}{*}{25} & \multirow{4}{*}{1 ano } & \multirow{4}{*}{ pública } & \multirow{4}{*}{02} \\
\hline & Apoio técnico & 03 & & & & \\
\hline & Professor & 13 & & & & \\
\hline & Supervisor & 08 & & & & \\
\hline
\end{tabular}

Fonte: Elaborado pelas pesquisadoras em análise aos editais disponíveis no portal da UFTM na internet em www.uftm.edu.br/pronatec2/processos-encerrados, busca "2013". 


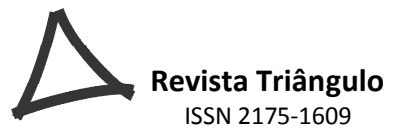

ISSN 2175-1609

Por meio da análise da Tabela 2 é possível observar a necessidade de planejamento adequado às realidades da instituição pelo número elevado de publicação de editais, somandose 8. No entanto, dessa vez, a variação de oferta de vagas foi melhor distribuída em comparação a 2012, com mínimo de 3 e máximo de 55 vagas. Nota-se que a partir do Edital 24, o terceiro do ano, os processos passaram a ter validade de 1 ano, no entanto ainda sem possibilidade de prorrogação. A destinação dos processos foi a característica que mais sofreu variações, em função de que neste ano foram pactuadas as ofertas de novos cursos técnicos os quais a instituição não possuía recursos humanos habilitados e capacitados para neles atuarem.

Dos processos destinados apenas a servidores públicos, tem-se: em dois deles foram selecionados apenas servidores com vínculo na UFTM, ativos ou aposentados; em outro, incluíram o IFTM; em outro, excluíram-se os aposentados do IFTM; e em outro, permanecendo excluídos os aposentados do IFTM, incluíram também os ativos da rede estadual de ensino. Os outros três editais desse ano, 24, 35 e 36, foram destinados ao público em geral pois indicavam necessidade de maiores opções de pessoal em função de que a maioria deles selecionou docentes e supervisores cujos requisitos para candidatura demandavam maior especificidade. A partir do Edital 5 publicado em março daquele ano, os processos passaram a contar com duas fases: a primeira eliminatória de análise curricular e a segunda, apenas classificatória, de entrevista. A inclusão dessa fase nos processos deu-se para sanar problemas nas seleções, sobretudo, relacionados a disponibilidade dos candidatos quanto aos horários de ofertas dos cursos.

Neste segundo ano foram selecionados professores para 107 novas disciplinas, sendo 13 delas (Edital 36) destinadas a cadastro de reserva em função do planejamento de possíveis novas pactuações. Foram selecionados também 25 supervisores de curso, 6 orientadores, 8 apoios administrativos que além de revezarem nas atividades de atendimento ao público e registro escolar, passaram também a revezar nas atividades de controle de estoques, repasse de auxílio estudantil ${ }^{5}$ e materiais impressos e 13 apoios técnicos que alternavam nas atividades acadêmicas dos cursos. Foram selecionados também 3 novas funções: 1 supervisor administrativo para gerenciar a equipe de apoio, 1 apoio de compras e 1 apoio de finanças, estes dois últimos, especificamente servidores da UFTM lotados nos respectivos setores, com 


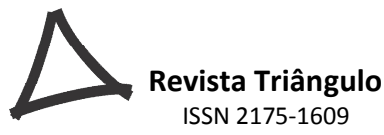

ISSN 2175-1609

vistas a maior celeridade nos processos de compras e de pagamentos aos fornecedores.

\subsection{Apogeu (2014)}

Conforme se observa no Relatório de Gestão do Exercício de 2014, a execução do programa na instituição chegou em seu apogeu neste ano, com uma estrutura notadamente ampliada, incluindo sede própria de $400 \mathrm{~m}^{2}$ em local distinto da sede do Cefores (UFTM, 2015), sendo possível inclusive estabelecer parcerias com outros projetos institucionais, como por exemplo o Complexo Cultural e Científico da UFTM, em Peirópolis, "visando desenvolver competências e habilidades profissionais e pessoais para adolescentes, jovens e adultos, através da aprendizagem profissional" (UFTM, 2015) e com o Setor de Capacitação de Pessoal da Pró-Reitoria de Recursos Humanos da UFTM, por meio da capacitação de servidores da instituição com a oferta do curso de Auxiliar Pedagógico.

Segundo este relatório, em 2014 foi possível pactuar a oferta de 77 novos cursos, sendo $23,38 \%$ técnicos e $76,62 \%$ de formação inicial e continuada. Tendo alcançado um quantitativo de 1624 matrículas em geral, a instituição conseguiu concluir 49 turmas do programa e levar ao êxito 477 alunos também do programa, sendo 21 destes nos cursos técnicos. Neste ano, ainda segundo este relatório, o Cefores teve um alunado regular de 338 alunos (UFTM, 2015), o que elevou o seu alunado geral para o número de 1962, sendo $82,77 \%$ vinculados ao programa e $17,23 \%$ matriculados regularmente.

Para sustentar o porte que o programa atingiu em 2014, outros processos de seleção de pessoal foram realizados. Por meio da análise da Tabela 3, a seguir, nesse ano é possível observar que houve um melhor planejamento de pessoal, com processos otimizados em menos editais, apenas 4. Contudo, as validades de todos os processos foram por períodos indeterminados que, teoricamente, resolveriam os problemas da instituição em lançar editais a cada 6 meses ou 1 ano. Se por um lado essa atitude deixou evidente o interesse da gestão na continuidade do programa, por outro, demonstrou inobservância a legislação ${ }^{6}$. 


\section{Revista Triângulo}

Tabela 3 - Processos seletivos de profissionais do Pronatec-UFTM no ano de 2014

\begin{tabular}{|c|c|c|c|c|c|c|}
\hline $\begin{array}{c}\text { Editais } \\
\text { PROEXT }\end{array}$ & Encargos & Vagas & Totais & Validade & Destinação & $\begin{array}{l}\text { Número } \\
\text { de fases }\end{array}$ \\
\hline \multirow{9}{*}{$\begin{array}{c}07 \mathrm{de} \\
06 / 02 / 2014\end{array}$} & Apoio sede & 01 & \multirow{9}{*}{95} & \multirow{9}{*}{$\begin{array}{c}\text { período } \\
\text { indeterminado }\end{array}$} & \multirow{9}{*}{ pública } & \multirow{9}{*}{02} \\
\hline & Serviços gerais & 01 & & & & \\
\hline & Apoio Remoto & 01 & & & & \\
\hline & Apoio finanças & 01 & & & & \\
\hline & Apoio técnico & 01 & & & & \\
\hline & Professor & 86 & & & & \\
\hline & Orient. jurídico & 01 & & & & \\
\hline & Orient.Psicoped. & 02 & & & & \\
\hline & Sup. Pedagógico & 01 & & & & \\
\hline \multirow{2}{*}{$\begin{array}{c}15 \mathrm{de} \\
22 / 04 / 2014\end{array}$} & Professor & 26 & \multirow{2}{*}{27} & \multirow{2}{*}{$\begin{array}{c}\text { período } \\
\text { indeterminado }\end{array}$} & \multirow{2}{*}{ pública } & \multirow{2}{*}{02} \\
\hline & Sup. Finanças & 01 & & & & \\
\hline $\begin{array}{c}16 \mathrm{de} \\
30 / 05 / 2014\end{array}$ & Professor & 06 & 06 & $\begin{array}{c}\text { período } \\
\text { indeterminado }\end{array}$ & pública & 02 \\
\hline $\begin{array}{c}17 \mathrm{de} \\
26 / 06 / 2014\end{array}$ & Professor & 08 & 08 & $\begin{array}{c}\text { período } \\
\text { indeterminado }\end{array}$ & pública & 01 \\
\hline
\end{tabular}

Fonte: Elaborado pelas pesquisadoras em análise aos editais disponíveis no portal da UFTM na internet em www.uftm.edu.br/pronatec2/processos-encerrados, busca " 2014 ".

Observa-se que o primeiro processo seletivo do ano, realizado em fevereiro, foi o mais robusto em quantidade de vagas, 95 no total, representando $69,85 \%$ do total das vagas daquele ano. Com exceção do Edital 17, todos os outros foram realizados em duas fases, o que demonstrou permanência da gestão na estratégia iniciada em 2013.

Outra diferença de 2014 foi que, a partir desse ano, não mais se realizou processo com destinação restrita a servidores públicos. Como consequência, longas filas de candidatos passaram a se formar à porta da sede do programa nos dias de inscrições, sendo preciso até mesmo recorrer à distribuição de senhas. Em função disso, os seus processos seletivos se assemelharam aos do próprio mercado de trabalho, e de uma possível visão de mercantilização da educação ${ }^{7}$, sobretudo, em função da fase de entrevista. $\mathrm{O}$ que os diferenciou, por se tratar de processos públicos, foi que todas essas entrevistas passaram a ser gravadas afim de que fosse possível ceder cópias das mesmas aos candidatos que desejassem entrar com recursos contra essa fase.

Neste terceiro ano foram selecionados professores para 126 novas disciplinas, 1 apoio administrativo para revezar com os demais nas atividades já mencionadas, 1 apoio técnico para novas atividades acadêmicas de cursos, mais 1 apoio de finanças para revezar com o que 


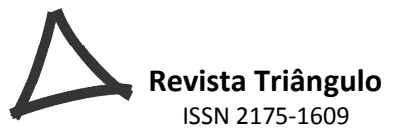

ISSN 2175-1609

foi selecionado em 2013 nos pagamentos aos fornecedores. Também foram selecionados outros 7 profissionais para 6 novas funções: 1 apoio para atuar em unidades remotas no controle de frequência de alunos e suporte aos supervisores e docentes, 1 orientador jurídico para dar assessoria, sobretudo aos processos seletivos, 2 orientadores psicopedagógicos para darem suporte às demandas que começaram a surgir com os alunos, 1 profisssional em serviços gerais para atuar na limpeza e manutenção da sede, 1 supervisor de finanças para gerenciar a equipe de apoio de finanças, e 1 supervisor pedagógico para acompanhar essa área juntamente com os docentes e supervisores de cursos.

\subsection{Equilíbrio e declínio (2015 e 2016)}

Os Relatórios das Gestões dos Exercícios de 2015 e 2016 não apresentaram os quantitativos do Pronatec, apenas os do Cefores. Afim de dar prosseguimento à análise, recorremos ao Setor de Registro Escolar do programa para que nos respondesse esses quantitativos. Sendo assim, obtivemos os dados constantes na Tabela 4, a seguir.

Tabela 4 - Indicadores do Pronatec-UFTM nos anos de 2015 e 2016

\begin{tabular}{l|c|c}
\hline \multicolumn{1}{c|}{ Indicadores } & $\mathbf{2 0 1 5}$ & $\mathbf{2 0 1 6}$ \\
\hline Cursos técnicos ofertados & 04 & 0 \\
\hline Cursos FIC ofertados & 13 & 20 \\
\hline Matrículas cursos técnicos & 113 & 81 \\
\hline Matrículas cursos FIC & 249 & 420 \\
\hline Turmas Técnico concluídas & 15 & 03 \\
\hline Turmas FIC concluídas & 15 & 21 \\
\hline Alunos diplomados nos cursos técnicos & 64 & 0 \\
\hline Alunos certificados nos cursos FIC & 111 & 280 \\
\hline
\end{tabular}

Fonte: Setor de Registro Escolar do Pronatec-UFTM

Por meio da análise dessa tabela, é possível observar que, no ano de 2015, sob o cenário político incerto referente ao Governo Federal no qual já se especulava um possível pedido de impedimento da então presidenta Dilma Rousseff, o Cefores pactuou 17 novos cursos, $23,53 \%$ de técnicos e outros $76,47 \%$ de qualificação. A instituição encerrou o ano com 362 alunos matriculados pelo programa, uma queda extremamente considerável em relação a 2014, o que já indicava uma nova fase na execução do mesmo não só na instituição, mas em 


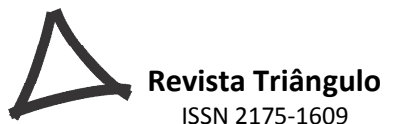

ISSN 2175-1609

todo o país. Dessas matrículas, 31,22\% referiam-se aos cursos técnicos e 68,78\% aos FICs. Foi possível concluir 30 turmas do programa divididas exatamente pela metade nessas duas modalidades. Obtiveram conclusão de seus cursos 175 alunos, sendo 36,57\% vindos dos cursos técnicos e $63,43 \%$ dos cursos FIC.

Segundo o Relatório de Gestão do Exercício de 2015 o Cefores conseguiu atingir a meta de 360 alunos em fevereiro matriculados regularmente. No entanto, em dezembro, fechou o ano com 281. Sendo assim, somando-se ao alunado com vínculo no programa, nesse período o Cefores teve um total de 643 alunos matriculados, 56,30\% com vínculo no programa e 43,70\% com vínculo regular (UFTM, 2016).

Outros processos seletivos de profissionais foram realizados para a continuidade do programa na instituição em 2015. A incerteza política desse ano também foi refletida nas seleções de pessoal, o que enfatizou a continuidade de ações planejadas, conforme é possível observar na Tabela 5, a seguir.

Tabela 5 - Processos seletivos de profissionais do Pronatec-UFTM no ano de 2015

\begin{tabular}{|c|c|c|c|c|c|c|}
\hline $\begin{array}{c}\text { Editais } \\
\text { PROEXT }\end{array}$ & Encargos & Vagas & Totais & Validade & Destinação & $\begin{array}{l}\text { Número } \\
\text { de fases }\end{array}$ \\
\hline \multirow{2}{*}{$\begin{array}{c}02 \mathrm{de} \\
28 / 01 / 2015 \\
\end{array}$} & Apoio técnico & 01 & \multirow{2}{*}{06} & \multirow{2}{*}{$\begin{array}{c}1 \text { ano e } \\
\text { prorrogável }\end{array}$} & \multirow{2}{*}{ pública } & \multirow{2}{*}{02} \\
\hline & Professor & 05 & & & & \\
\hline \multirow{3}{*}{$\begin{array}{c}08 \mathrm{de} \\
13 / 04 / 2015\end{array}$} & Professor & 54 & \multirow{3}{*}{72} & \multirow{3}{*}{$\begin{array}{c}1 \text { ano, } \\
\text { prorrogado } \\
\text { até } 05 / 2017\end{array}$} & \multirow{3}{*}{ pública } & \multirow{3}{*}{02} \\
\hline & Apoio técnico & 16 & & & & \\
\hline & Supervisor & 02 & & & & \\
\hline \multirow{5}{*}{$\begin{array}{c}11 \mathrm{de} \\
24 / 06 / 2015\end{array}$} & Professor & 26 & \multirow{5}{*}{40} & \multirow{5}{*}{$\begin{array}{c}1 \text { ano e } \\
\text { prorrogável }\end{array}$} & \multirow{5}{*}{ pública } & \multirow{5}{*}{02} \\
\hline & Supervisor & 08 & & & & \\
\hline & Sup. Administ. & 01 & & & & \\
\hline & Apoio compras & 02 & & & & \\
\hline & Apoio técnico & 03 & & & & \\
\hline \multirow{3}{*}{$\begin{array}{c}12 \mathrm{de} \\
25 / 09 / 2015\end{array}$} & Apoio técnico & 02 & \multirow{3}{*}{30} & \multirow{3}{*}{$\begin{array}{c}1 \text { ano, } \\
\text { prorrogado } \\
\text { até } 10 / 2017\end{array}$} & \multirow{3}{*}{ pública } & \multirow{3}{*}{02} \\
\hline & Apoio remoto & 01 & & & & \\
\hline & Professor & 27 & & & & \\
\hline
\end{tabular}

Fonte: Elaborado pelas pesquisadoras em análise aos editais disponíveis no portal da UFTM na internet em www.uftm.edu.br/pronatec2/processos-encerrados, busca "2015".

Nota-se que foram realizados apenas 4 processos em datas estratégicas com respectivas validades passadas para 1 ano, prorrogável por igual período. Isso se deve, sobretudo, ao trabalho de orientação jurídica selecionado em 2014. A instituição abriu um 


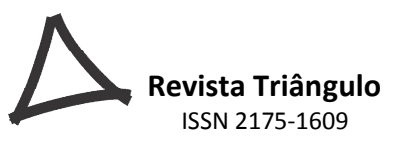

total de 148 vagas de pessoal em 2015. O primeiro edital ocorreu em janeiro, com poucas vagas (4,05\%), para complementação de pessoal para funcionamento dos cursos que já estavam em execução. O segundo, somente em abril, em função da proximidade da data da nova pactuação, com o número maior de vagas $(48,65 \%)$. O terceiro em junho, com $27,03 \%$ das vagas do ano, em função da necessidade de pessoal para os cursos técnicos que iniciariam um novo semestre. E o último processo em setembro, com 20,27\% das vagas do ano, para complementação de pessoal até o findar do mesmo e início do próximo. De fato, dois de seus editais (08 e 12) tiveram suas validades prorrogadas como estratégia de contingenciamento de gastos, o que representou em prorrogação de vigência de 68,92\% dos selecionados no ano. A gestão permaneceu com as estratégias de processos em duas fases e abertos aos públicos interno e externo em todos os processos.

Neste quarto ano de execução do programa na instituição foram selecionados professores para 112 novas disciplinas, 22 apoios técnicos para as atividades acadêmicas, 2 apoios de compras para revezar com o que foi selecionado em 2013, 1 apoio remoto, 1 supervisor administrativo e 10 supervisores de cursos. Não tendo nenhuma nova função criada nesse ano, ao final do mesmo, a incerteza em relação ao cenário político só aumentou em detrimento do aceite pela Câmara dos Deputados de denúncia de crime de responsabilidade contra a então Presidenta Dilma Rousseff, deixando duvidosas as expectativas sobre o futuro do programa.

Voltando aos dados da Tabela 4, agora para o ano de 2016, é possível analisar que sob esse cenário político instável, o Cefores pactuou 20 novos cursos, porém todos de qualificação. A instituição encerrou o ano com 501 alunos matriculados pelo programa que representou uma alta de 38,40\% em relação a 2015, cujo impacto não foi considerável em detrimento da não-pactuação de nenhuma nova turma de curso técnico. Dessas matrículas, $16,17 \%$ referiam-se aos cursos técnicos já existentes e $83,83 \%$ aos FIC, tanto antigos quanto novos. Foi possível concluir 24 turmas do programa (3 técnicos e 21 FIC). Obtiveram conclusão de seus cursos 280 alunos de cursos FIC e nenhum de técnicos. Segundo o Relatório de Gestão do Exercício de 2016 o Cefores atingiu, em agosto, o total de 407 alunos matriculados regularmente (UFTM, 2017). Nesse mesmo mês, ocorreu a efetivação do impedimento da Presidenta Dilma e consequente transferência da responsabilidade do 


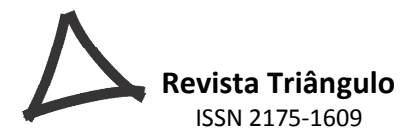

Governo Federal para o então Vice-Presidente Michel Temer. Já em dezembro, a instituição fechou o ano com 321 alunos matriculados por meio de processos regulares. Considerando os números desse período, foi possível chegar a um total de 822 alunos matriculados, $60,95 \%$ com vínculo no programa e 39,05\% com vínculo regular. Em função dessa instabilidade política, as seleções também sofreram impacto nesse ano, como pode ser observado na tabela a seguir.

Tabela 6 - Processos seletivos de profissionais do Pronatec-UFTM no ano de 2016

\begin{tabular}{|c|c|c|c|c|c|c|}
\hline $\begin{array}{c}\text { Editais } \\
\text { PROEXT }\end{array}$ & Encargos & Vagas & Totais & Validade & Destinação & $\begin{array}{l}\text { Número } \\
\text { de fases }\end{array}$ \\
\hline \multirow{13}{*}{$\begin{array}{c}01 \mathrm{de} \\
10 / 03 / 2016\end{array}$} & Apoio atend. & 03 & \multirow{13}{*}{41} & \multirow{13}{*}{$\begin{array}{l}1 \text { ano, } \\
\text { prorrogado } \\
\text { até } 04 / 2018\end{array}$} & \multirow{13}{*}{ pública } & \multirow{13}{*}{02} \\
\hline & Apoio pedag. & 03 & & & & \\
\hline & Apoio registro & 03 & & & & \\
\hline & Apoio inform. & 01 & & & & \\
\hline & Apoio RH & 01 & & & & \\
\hline & Apoio jurídico & 01 & & & & \\
\hline & Apoio técnico & 02 & & & & \\
\hline & Serviços gerais & 02 & & & & \\
\hline & Professor & 18 & & & & \\
\hline & Orientador & 02 & & & & \\
\hline & Orient.Psicoped. & 01 & & & & \\
\hline & Supervisor & 03 & & & & \\
\hline & Sup. Pedagógico & 01 & & & & \\
\hline $\begin{array}{c}05 \mathrm{de} \\
13 / 07 / 2016\end{array}$ & Professor & 21 & 21 & $\begin{array}{c}1 \text { ano } \\
\text { prorrogável }\end{array}$ & pública & 02 \\
\hline $\begin{array}{c}09 \mathrm{de} \\
17 / 10 / 2016\end{array}$ & Professor & 08 & 08 & $\begin{array}{c}1 \text { ano } \\
\text { prorrogável }\end{array}$ & pública & 02 \\
\hline
\end{tabular}

Fonte: Elaborado pelas pesquisadoras em análise aos editais disponíveis no portal da UFTM na internet em www.uftm.edu.br/pronatec2/processos-encerrados, busca "2016".

Com apenas 3 processos seletivos, em datas pontuais (no começo, no meio e no fim do ano), a instituição ofertou 70 vagas em 2016, o que representou 47,30\% das que foram ofertadas em 2015, ou seja, menos da metade. Permanecendo com as estratégias de processos abertos, de duas fases e de validade de 1 ano prorrogável por igual período, com efeito, a gestão conseguiu conduzir o programa durante um ano de novas complexidades políticas. $\mathrm{O}$ processo mais robusto (Edital 01), prorrogado até abril de 2018, representou em dilação de vigência de 58,57\% dos selecionados no ano. Foram selecionados outros 12 apoios administrativos, cujas nomenclaturas dos encargos foram apresentadas com identificação das 


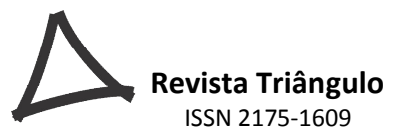

ISSN 2175-1609

atividades a serem desempenhadas: atendimento, informática, jurídicas, pedagógicas, registrais e de recursos humanos. Evidentemente, a maioria dos profissionais já existentes e ocupantes do encargo de apoio administrativo já revezavam nessas atividades, embora não tenham sido selecionados especificamente para elas. A estratégia, nesse ano, foi exatamente essa, determinar com especificidade as funções de cada um. Foram selecionados também, outros 2 apoios técnicos, 1 orientador psicopedagógico, 2 orientadores, 2 profissionais de serviços gerais, 1 supervisor pedagógico, 3 supervisores de cursos, além de professores para 47 novas disciplinas. Ao final do ano permanecia, portanto, uma fase de instabilidades e incertezas quanto à execução do programa não só na UFTM, mas em todas as instituições ofertantes do país.

Desde o início do programa o Cefores ofertou os seguintes cursos técnicos: Açúcar e Álcool, Análises Clínicas, Computação Gráfica, Edificações, Enfermagem, Estética, Farmácia, Geologia, Imagem Pessoal, Instrumentos Musicais, Informática, Informática para Internet, Meio Ambiente, Química, Rede de Computadores e Segurança do Trabalho, além de inúmeros cursos na modalidade de formação inicial e continuada divididos nos seguintes eixos tecnológicos: Ambiente, Saúde e Segurança; Apoio Educacional; Controle e Processos Industriais; Gestão e Negócios; Hospitalidade e Lazer; Informação e Comunicação; Infraestrutura; Produção Cultural e Design e Recursos Naturais.

\section{CONSIDERAÇÕES FINAIS}

Ao término desta pesquisa constatou-se que a implantação do Pronatec no Cefores foi fundamental para confirmar sua identidade de instituição de educação profissional no âmbito da UFTM, bem como em nível local e regional.

O expressivo número de alunos matriculados, que chegou a superar o alunado regular da instituição, demonstra o interesse da população em qualificar-se profissionalmente e indica a demanda pelos cursos ofertados que, por sinal, foram bastante diversificados e em consonância com as necessidades pontuais do mercado de trabalho. A variedade de cursos, que foi além daqueles ofertados usualmente pelo Cefores, está intrinsecamente relacionada à possibilidade de contratação, via processo seletivo, de profissionais para atuarem nos 


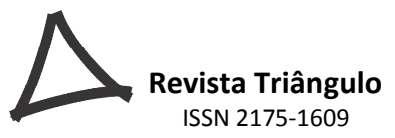

mesmos. Por esse motivo, a oferta de vagas para seleção de pessoal também ganhou destaque na análise aqui realizada.

Outros resultados, mais específicos, ainda podem ser observados. Os números de matrículas e de vagas para seleções de pessoal sofreram variações ano a ano que condizem com a realidade política do período, conforme se observa na Tabela 7, a seguir.

Tabela 7 - Evolução da implantação e execução do Pronatec no Cefores em números de matrículas e seleções de pessoal no período de 2012 a 2016.

\begin{tabular}{l|c|c|c|c|c}
\hline \multicolumn{1}{c|}{ Indicadores } & $\mathbf{2 0 1 2}$ & $\mathbf{2 0 1 3}$ & $\mathbf{2 0 1 4}$ & $\mathbf{2 0 1 5}$ & $\mathbf{2 0 1 6}$ \\
\hline Matrículas & 228 & 735 & 1624 & 362 & 501 \\
\hline Vagas para seleções de pessoal & 57 & 163 & 136 & 148 & 70 \\
\hline
\end{tabular}

Fonte: Elaborado pelas pesquisadoras com fundamento nas informações obtidas durante a pesquisa.

O ano de 2012, início do programa no Cefores, pode ser considerado o ano do aprendizado, com os números mais baixos do período. O ano de 2013, o do crescimento, com uma transição que representou uma alta de $222,37 \%$ em número de matrículas e de $185,96 \%$ em vagas para seleções de pessoal. O ano de 2014 foi o do apogeu. Embora tenha ocorrido uma redução no número de vagas para seleção de pessoal de ordem de $16,56 \%$ em relação a 2013, o número de matrículas cresceu substancialmente em 120,95\% e que, se comparados com o da implantação do programa passam para o percentual $612,28 \%$.

Por outro lado, em função do cenário político incerto, a partir de 2015 um novo contexto se formou. Esse ano foi considerado o do equilíbrio. A redução de 77,71\% nas matrículas em contraponto com o aumento de 8,82\% nas vagas de seleções de pessoal, correspondeu à posição da gestão da instituição na manutenção do programa, sobretudo, na conclusão das turmas pactuadas e ainda ativas.

O ano de 2016 foi considerado o do início do declínio da execução. A alta de 38,40\% em número de matrículas não representou, de fato, um avanço em função de que sua composição foi integralmente originada de cursos de formação inicial e continuada. Os cursos que, de fato, demandaram um maior esforço por parte da instituição, com aulas de segunda a sexta-feira (ou seja, os cursos técnicos), não tiveram nenhuma vaga ofertada. Por outro lado, a redução de 52,70\% nas vagas para seleções de pessoal nesse ano reafirma que a situação era de cautela, revelando uma gestão mais comedida. 


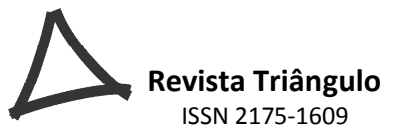

Uma forma mais fácil de entender a evolução vivida pelo Cefores com o Pronatec é fazer uma analogia com as fases pelas quais nós, seres humanos, passamos em nossas vidas. O nascimento do programa em 2012 foi a fase do puerpério na qual tudo é novidade e a obrigação de adaptação às mudanças é quesito essencial para a sobrevivência. Em 2013 foi o ano da infância, fase em que o crescimento se dá de maneira extremamente rápida. Em 2014 veio a adolescência, trazendo muitas conquistas e novas descobertas. O ano de 2015 foi considerado o da fase adulta com alto nível de maturidade. E, por fim, em 2016, a fase da velhice, na qual as atividades são reduzidas no intuito maior de aproveitamento dos esforços empenhados nas outras fases.

Retomando a perspectiva dos autores analisados acerca das políticas públicas voltadas para a educação profissional, depreende-se que, no caso do Pronatec, foram as questões políticas e econômicas que direcionaram as tomadas de decisões, e não as necessidades de formação e educação dos jovens e adultos. A análise dos números apresentados corrobora essa afirmativa, já que o declínio do Pronatec foi motivado pela instabilidade no cenário político, e não por desinteresse da população.

Cabe ressaltar que uma nova pesquisa pode ser visualizada com um recorte temporal a partir de 2017, visto que, de fato, até o momento o fim do programa não aconteceu de forma oficial, e a execução do mesmo permaneceu por além deste ano, no âmbito da instituição, que continuou tomando suas decisões paulatinamente, conforme as determinações do Ministério da Educação no governo Michel Temer. Também em continuidade a essa pesquisa seria interessante entrevistar os egressos para verificar até que ponto o curso feito favoreceu sua formação e/ou qualificação profissional, bem como a inserção no mercado de trabalho, seja como empregado ou como empreendedor.

Considerando que o corpus empírico selecionado para esta pesquisa limitou-se a uma única instituição ofertante do Pronatec, espera-se que esse trabalho possa somar-se a outros que analisaram instituições distintas, sendo possível, assim, compor um cenário da oferta deste programa que marcou a gestão federal no período delimitado, evidenciando tanto suas potencialidades como suas falhas, que poderão servir de embasamento para a implantação e execução de futuros programas voltados para a educação profissional no Brasil. 


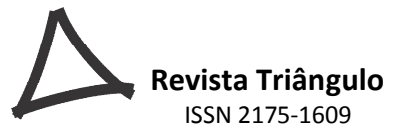

\section{NOTAS}

1. Os dados coletados nos relatórios de gestão são referentes a data de 31 de dezembro de cada exercício.

2. Para o cômputo das cargas horárias de quaisquer de seus cursos, o programa considera que uma hora deve ser de efetivos 60 minutos, e não 50, como ocorre usualmente nas instituições educacionais.

3. PROEXT (Pró-Reitoria de Extensão Universitária da UFTM).

4. Como nos processos que selecionaram docentes, os mesmos poderiam se candidatar para até 4 disciplinas em um mesmo edital, não é possível mensurar a quantidade de docentes selecionados por meio apenas da análise dos editais. Para tanto, recomenda-se nova pesquisa, a partir dos resultados finais de cada processo.

5. A atividade de repasse de auxílio estudantil variou, durante toda a implementação do programa na instituição. Iniciou através do repasse dos lanches e vales-transportes, passou para o repasse do pecúnio e depois voltou para o repasse inicial. No entanto, não é possível precisar as datas desses períodos por meio dos documentos analisados. Para tanto, recomenda-se análise em campo juntamente com os profissionais de apoio de compras, orçamento e finanças.

6. O inciso III do Artigo 37 da Constituição Federal preconiza a obediência pela administração pública, direta e indireta, e de quaisquer dos poderes, em estabelecer prazo de validade de até 2 anos, prorrogável por igual período para quaisquer concursos públicos por ela promovidos (BRASIL, 1988).

7. Expressão utilizada, no campo da educação, para conceituar quando a mesma está sendo tratada como uma mercadoria. Para um melhor entendimento da expressão recomenda-se a leitura do artigo Problemas da Educação Profissional do Governo Dilma: PRONATEC, PNE E DCNEMs, de autoria do professor Marcelo Lima, cuja referência se encontra listada ao final deste artigo.

\section{REFERÊNCIAS}

BRANDÃO, Marisa. Educação profissional e ensino superior: do governo FHC ao governo Lula. Cadernos CEMARX: Centro de Estudos Marxistas, Campinas, n. 6, p. 189-204, 2009.

BRASIL. Constituição da República Federativa do Brasil de 1988. Disponível em: $<$ http://www.planalto.gov.br/ccivil_03/constituicao/constituicao.htm>. Acesso em: 01 ago. 2018.

. Lei ${ }^{0} 12.513$ de 26 de outubro de 2011: institui o Programa Nacional de Acesso ao Ensino Técnico e Emprego (Pronatec); [...]; e dá outras providências. Disponível em: $<$ http://www.planalto.gov.br/ccivil_03/_ato2011-2014/2011/lei/112513.htm>. Acesso em: 21 jul. 2018.

. Programa de rádio: Café com o Presidente. 2011. Entrevista concedida à Rádio Nacional em 9 de maio de 2011. Disponível em: < http://www.brasil.gov.br/editoria/educacaoe-ciencia/2011/02/cafe-com-a-presidenta-governo-cria-incentivos-para-formacao-tecnica-de- 


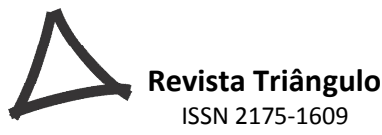

ISSN 2175-1609

jovens-e-trabalhadores>. Acesso em: 21 jul. 2018.

. Portaria $\mathrm{n}^{0} 817$ de 13 de agosto de 2015: dispõe sobre a oferta da BolsaFormação no âmbito de Programa Nacional de Acesso ao Ensino Técnico e Emprego Pronatec, de que trata a Lei 12.513, de 26 de outubro de 2011, e dá outras providências. Disponível em: <http://portal.mec.gov.br/index.php?option=com_docman\&view $=$ download\&alias=18043-14-8-15port-817\&category_slug=agosto-2015-df\&Itemid=30192>. Acesso em: 21 jul. 2018.

CASTRO, MadAna Desirée Ribeiro de Castro; BARBOSA, Sebastião Cláudio. Política e gestão da educação profissional e tecnológica: a construção de uma nova institucionalidade para a Rede Federal de Educação Profissional e Tecnológica em tempos da acumulação flexível. XXI Simpósio Brasileiro de Política e Administração da Educação, Recife, 2013. Disponível em: <http:/www.anpae.org.br/simposio26/1comunicacoes/

MadAnaDesireeRibeirodeCastro-ComunicacaoOral-int.pdf>. Acesso em: 20 jul. 2018.

LIMA, Marcelo. Problemas da Educação Profissional do Governo Dilma: Pronatec, PNE e DCNEMs. Trabalho \& Educação, Belo Horizonte, v.21, n.2, p.73-91, mai./ago. 2012.

PNP. Plataforma Nilo Peçanha 2018: Ano Base 2017. Rede Federal de Educação

Profissional, Científica e Tecnológica, 2018. Disponível em

$<$ https://www.plataformanilopecanha.org/>. Acesso em 30 jul. 2018.

REIS, Cinval Filho dos. Educação profissional em debate: da crise financeira mundial de 2008 ao arranjo institucional do Pronatec. Tese (Doutorado em Educação). Universidade Federal de Uberlândia, Uberlândia, 2017.

UFTM. Relatório de Gestão do Exercício de 2012, 2013. Disponível em $<$ http://uftm.edu.br /proplan/prestacao-de-contas/relatorios-de-gestao>. Acesso em: 24 jul. 2018.

. Relatório de Gestão do Exercício de 2013, 2014. Disponível em

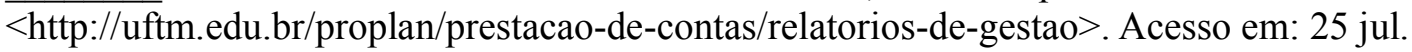
2018.

. Relatório de Gestão do Exercício de 2014, 2015. Disponível em

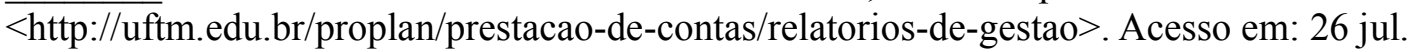
2018 .

Relatório de Gestão do Exercício de 2015, 2016. Disponível em

$\overline{<\mathrm{http}: / / \mathrm{uftm}}$.edu.br/proplan/prestacao-de-contas/relatorios-de-gestao $>$. Acesso em: $27 \mathrm{jul}$. 2018.

. Relatório de Gestão do Exercício de 2016, 2017. Disponível em

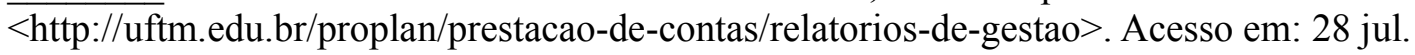
2018. 